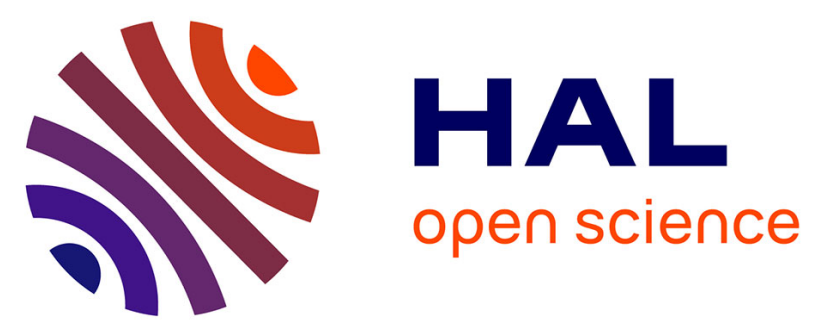

\title{
Tropical cyclone genesis over the western North Pacific impacted by SST anomalies from other basins while El Niño decays
}

Jin-hua Yu, Lijian Ou, Lin Chen, Laurent Li, Ming Sun, Xiaoyao Zhong, Xuyu Zhang

\section{To cite this version:}

Jin-hua Yu, Lijian Ou, Lin Chen, Laurent Li, Ming Sun, et al.. Tropical cyclone genesis over the western North Pacific impacted by SST anomalies from other basins while El Niño decays. Quarterly Journal of the Royal Meteorological Society, 2021, 147 (737), pp.2580-2596. 10.1002/qj.4042 . hal03447278

\section{HAL Id: hal-03447278 \\ https://hal.science/hal-03447278}

Submitted on 24 Nov 2021

HAL is a multi-disciplinary open access archive for the deposit and dissemination of scientific research documents, whether they are published or not. The documents may come from teaching and research institutions in France or abroad, or from public or private research centers.
L'archive ouverte pluridisciplinaire $\mathbf{H A L}$, est destinée au dépôt et à la diffusion de documents scientifiques de niveau recherche, publiés ou non, émanant des établissements d'enseignement et de recherche français ou étrangers, des laboratoires publics ou privés. 


\title{
Tropical cyclone genesis over the Western North Pacific impacted by SST anomalies from other basins while El Niño decays
}

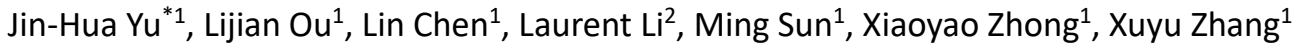 \\ ${ }^{1}$ Key Laboratory of Meteorological Disaster, Ministry of Education (KLME)/ \\ Collaborative Innovation Center on Forecast and Evaluation of Meteorological Disasters (CIC- \\ FEMD), Nanjing University of Information Science and Technology, Nanjing 210044, China \\ ${ }^{2}$ Laboratoire de Météorologie Dynamique, CNRS, Sorbonne Université, Ecole Normale Supérieure, \\ Ecole Polytechnique, Paris, France
}

Submitted to QJRMS in December 2020

\begin{abstract}
${ }^{*}$ Corresponding author address: Dr. Jin-Hua Yu, Key Laboratory of Meteorological Disaster of Ministry of Education/School of Atmospheric Science, Nanjing University of Information Science and Technology, Nanjing, 210044. Email: jhyu@nuist.edu.cn; jhyu64@163.com
\end{abstract}




\begin{abstract}
Tropical cyclone (TC) genesis over the Western North Pacific (WNP) in the TC active season July-October after El Niño peaks in preceding December is revealed to be either deficit or excedent, depending on how El Niño is able to remotely create and maintain sea surface temperature (SST) anomalies in the North Atlantic and Indian Ocean during spring while El Niño decays. A reduction of TC genesis (Group 1) is coincident with a warming in the Indian Ocean and a positive tripolar SST pattern in the North Atlantic, while enhanced TC genesis (Group 2) corresponds to the configuration without significant SST anomalies in the North Atlantic and in the Indian Ocean. Relevant physical mechanisms are investigated through observational data analysis and confirmed with model simulations. In Group 1, EI Niño SST anomalies enhance convection over the central-eastern equatorial Pacific. The related latent heat release excites Rossby wave trains which can efficiently propagate energy from the eastern tropical Pacific into Central America and further into the subtropical North Atlantic. The warm SST anomalies found in the Indian Ocean and in the North Atlantic can force robust anomalous easterlies in the tropical WNP, producing unfavorable dynamic and thermodynamic conditions for TC genesis. Group 2 shows a quite distinct situation. Actually, the late winter anomalous westerlies are much weaker over Central America in Group 2, providing a configuration of inhibition for an efficient wave energy propagation from the tropics into the subtropical North Atlantic. The warm SST over the Maritime Continent is then responsible for the increase of TC genesis over the South China Sea and around the Philippines through exciting a cyclonic circulation in the TC active season.
\end{abstract}

Key words: Tropical cyclone genesis; El Niño decaying phase; North Atlantic capacitor; Indian Ocean capacitor 


\section{Introduction}

El Niño-Southern Oscillation (ENSO) is an important climate variability and provides interannual predictability. Due to its high sensitivity to Sea-Surface Temperature (SST), the tropical cyclone (TC) genesis is believed to have a strong relationship with ENSO, which constitutes a hot topic for the scientific community. The TC genesis over the western North Pacific (WNP) is particularly sensitive to El Niño due to the geographic proximity. El Niño is generally accompanied by an eastward extension of the convection active zone in the Tropical Pacific (Vecchi and Harrison 2006), which favors TC genesis in the southeastern zone of WNP, and increases lifetime and intensity of TC (Camargo et al. 2007; Chia and Ropelewski 2002; Krishnamurthy et al. 2016; Wang and Chan 2002). A lagged negative correlation was however identified between El Niño mature stage Niño3.4 index and lagged TC genesis over the WNP during the decaying phase of El Niño (Li 2012). Beyond El Niño, the TC genesis in the WNP is also effectively affected by SST anomalies in other oceanic basins, including the Indian Ocean (Zhan et al. 2014), the North Atlantic (Huo et al. 2015; Yu et al. 2016a, b), and, a wider zone of the Eastern Tropical Pacific (e.g., the Pacific meridional mode, Zhang et al. 2016).

Under the same appellation El Niño, there is actually a large diversity with different SST anomalies at mature stage and different SST evolutions after the peak. Recent studies reported salient differences of TC genesis between two super El Niño events (the one of 1997-1998 against that of 2015-2016). The differences are particularly remarkable during the decaying phase of El Niño (Chen and Wang. 2018; Wu et al. 2018; Zhan et al. 2017). It remains however largely unclear what contributes to such differences.

El Niño events typically develop during boreal spring and summer, peak in winter, and decay in the following spring. They may excite teleconnections in other oceanic basins through atmospheric bridges, delaying the spring warming of the tropical Indian Ocean and North Atlantic (Alexander et al. 2002; Enfield and Mayer 1997; Klein et al. 1999; Yang et al. 2007; García-Serrano et al. 2017; Saravanan and Chang 2000; Yeh et al. 2018). The warming over the eastern tropical Indian Ocean is associated with suppressed evaporation and intensified incoming solar radiation at the surface, consequence of the anomalous subsidence of the Walker circulation. The ocean dynamics however plays an important role for keeping warm SST anomalies in the western Indian Ocean (Huang and Kinte 2002; Klein et al. 1999; Tokinaga and Tanimoto 2004; Webster et al. 1999). The spring warming of the tropical Indian Ocean acts like a charged capacitor excited by El Niño during the preceding winter. The warming persists through summer, and produces its effects like a discharging capacitor (Yang et al. 2007, Xie et al. 2009). Actually, warm SST over the tropical Indian Ocean can cause tropospheric temperature to increase by a moistadiabatic adjustment of deep convection, and force a warm equatorial Kelvin wave to the east. A low surface pressure is produced over the western equatorial Pacific. Surface friction drives northeasterly winds into this equatorial low pressure, inducing surface divergence and suppressing deep convection in 
the subtropical WNP. This process is called Kelvin wave-induced Ekman divergence in Xie et al. (2009) and can be amplified by the circulationconvection feedback, maintaining the anomalous anticyclone over the WNP. Li et al. (2017) suggested that the tropical Atlantic may also have a capacitor effect, similar to that of the Indian Ocean following an El Niño event. These capacitor effects, from both oceanic basins of the Indian Ocean and Atlantic, could initiate and maintain an anticyclonic circulation over the Philippine Sea (Wang et al. 2000; Wang and Zhang 2002), thus weakening the monsoon trough and suppressing TC genesis over the WNP during the summer following an El Niño (Du et al. 2011).

El Niño-induced atmospheric circulation anomalies can force a delayed (relative to the peak of El Niño) warming of the tropical North Atlantic through the weakening of northeasterly trade winds and the subsequent surface evaporation (Giannini et al. 2001). A few mechanisms were formulated to explain the southwesterly anomalies over the tropical North Atlantic and their link to El Niño, including the extratropical Rossby wave train (Alexander et al. 2002), the eastward shift of the Walker circulation and changes of the Atlantic Hadley cell (Klein et al. 1999), the eastward propagation of a warm Kelvin wave (Lintner and Chiang 2007) and a remote Gill-type response to the El Niño-induced, zonally compensated heat source over the Amazon basin (GarcíaSerrano et al. 2017). Apart from the decrease of wind-related evaporative cooling, a reduction of cloudiness, associated with both the descending branch of the anomalous Walker circulation and the atmospheric Pacific/North American teleconnection pattern (Wallace and Gutzler 1981), also contributes to the warming of the tropical North Atlantic in spring via enhanced incoming solar radiation at the ocean surface (García-Serrano et al. 2017; Klein et al. 1999; Lau and Nath 2001).

Xie et al. (2009) assessed the role of remote forcing for the maintenance of the subtropical anticyclone in the central WNP in the summer of decaying El Niño. For this stage of El Niño that can be qualified as post-El Niño period, precipitation anomalies are no more significantly correlated with local SST variation. We can thus reasonably hypothesize that remote forcing can be from other oceanic basins, in particular, from the tropical Indian Ocean (Wu et al. 2010) and from the North Atlantic. Our main objective is to address the linkage between ENSO and SST changes over the North Atlantic and the tropical Indian Ocean for the post-El Niño time, and to investigate any influences on modulating TC genesis in the WNP.

SST anomalies of the tropical North Atlantic seem to play a much more important role than previously thought, even in determining SST anomalies over the whole extratropical North Atlantic (Wu et al. 2007). Furthermore, Czaja and Marshall (2002) demonstrated that the tropical North Atlantic SST variability may be largely a response to the North Atlantic Oscillation (NAO) and to ENSO remote forcing. The tripolar anomalous SST pattern is the leading mode of SST variation in the North Atlantic at interannual timescale (Czaja and Marshall 2001; Han et al. 2016; Yu et al. 2016b). It basically shows SST anomalies of opposite sign on both north and south sides of the mean position of the Gulf Stream. 
We explore the hypothesis that the TC genesis in the WNP in the season following El Niño mature stage is modulated by SST anomalies from both the Indian Ocean and the North Atlantic, which are ultimately the consequence of the delayed capacitor effect of the preceding El Niño event in the tropical Pacific. We can then explain why different El Niño events, with similar spatial patterns and amplitudes until their mature phase, can induce different SST evolution courses in the North Atlantic and Indian Ocean in their decaying phase, and ultimately exert different impacts on the WNP TC genesis. The following of the paper is organized with a description of data and methodology given in Section 2. Sections 3 to 5 present results of different steps of our investigation, with a first focus (Section 3) on SST evolution trajectories when EI Niño events are stratified by deficit or excedent TC genesis over the WNP for the TC active season July-October after the peak of El Niño. With the TC genesis as a discriminant parameter, Section 4 shows different teleconnection configurations transmitting signals from the tropical Pacific to North Atlantic and Indian Ocean. Section 5 presents a thorough analysis of different atmospheric fields playing a role in the TC genesis in WNP, completed by outputs from a climate model with properlydesigned simulations to provide a further piece of evidence for our working hypothesis. Conclusions and discussions are given in Section 6.

\section{Data and Methodology}

\subsection{Data}

The Tropical Cyclone Best-Track Archive from the Joint Typhoon Warning Center (https://www.metoc.navy.mil/jtwc/jtwc.html?best-tracks) includes the position (latitude and longitude) and maximum sustained wind speed at six-hour interval. A TC is counted as an event of TC genesis in WNP $\left(0^{\circ}-40^{\circ} \mathrm{N}, 100^{\circ} \mathrm{E}-180^{\circ}\right)$ if it is originally formed over the area and its maximum sustained speed reaches $17.2 \mathrm{~m} \mathrm{~s}^{-1}$ (tropical storm category). Our analyses cover the period from 1970 to 2016 during which more reliable satellite observations over the open oceans are available (Franklin et al. 2003), and focus on the TC season from July to October. The total number of TCs counted during the active season is considered as a measure of the TC genesis. An anomaly of TC genesis designates its departure from its climatology from 1970 to 2016 . The same notion of climatology also applies to other variables throughout our study. Besides the TC data, other monthly or daily atmospheric variables at standard pressure levels and surface precipitation amounts, with a horizontal resolution of $2.5^{\circ}$, are from the National Centers for Environmental Prediction and the National Center for Atmospheric Research Reanalysis 1 (Kalnay et al. 1996). We define the vertical wind shear as the difference of wind speeds between 200 and $850 \mathrm{hPa}$. Global monthly SST data at a horizontal resolution of $1^{\circ}$ are from the Met Office Hadley Centre (Rayner et al. 2003).

We identify an El Niño event when the anomalous NIÑO3.4 index (departure from its climatological mean during 1970 - 2016), the averaged SST anomaly in the NIÑO3.4 region $\left(5^{\circ} \mathrm{S}-5^{\circ} \mathrm{N}, 170^{\circ}-120^{\circ} \mathrm{W}\right)$ from June to the following May, is greater than $0.5^{\circ} \mathrm{C}$ and there is at least one month with an anomaly greater than $1{ }^{\circ} \mathrm{C}$. This definition, 
slightly different from that suggested by Trenberth (1997), provides however a relevant measure for both intensity and duration of an El Niño event (Wang et al. 2017). Ten El Niño events were identified: 1972-1973, 1977-1978, 1982-1983, 1987-1988, 19911992, 1994-1995, 1997-1998, 2002-2003, 2009-2010 and 2015-2016. In this study, eight out of the ten El Niño events will be selected based on TC genesis anomalies following EI Niño peak. An Indian Ocean SST index is defined as the average SST over the region $20^{\circ} \mathrm{S}-20^{\circ} \mathrm{N}, 40^{\circ}-100^{\circ} \mathrm{E}$. A North Atlantic tripolar mode index is defined as an average of the SST in the tropical region $\left(10^{\circ}-20^{\circ} \mathrm{N}, 50^{\circ}-20^{\circ} \mathrm{W}\right)$ and the middle-high latitude region $\left(40^{\circ}-55^{\circ} \mathrm{N}, 60^{\circ}-30^{\circ} \mathrm{W}\right)$ minus that in the subtropical region $\left(25^{\circ}-35^{\circ} \mathrm{N}, 80^{\circ}-50^{\circ} \mathrm{W}\right)$, similar to that of Czaja and Marshall (2001). Once events identified and selected with relevant criteria satisfied, we mainly use the compositing technique to investigate the common feature. Statistical significance of composite analyses is estimated according to a two-tailed Student's $t$ test for all relevant variables.

\subsection{Numerical simulations with a climate model}

We employ ECHAM6.3 model, the sixth generation of the atmospheric general circulation model ECHAM (Stevens et al. 2015) for our sensitivity simulations. The model's horizontal resolution is of T63 and there are 47 levels in the vertical. ECHAM6.3 is forced with observed monthly climatological SST and sea ice, and run for 30 years (considered as 30 ensemble members) in the control simulation. Each of our sensitivity simulations is run identically as the control simulation with the same configuration and same initial state, but with specially-designed SST anomalies (as detailed in Section 5) added into the climatological SST. The 30-year duration of numerical runs provides a robust climatology, allowing to assess the response of atmospheric circulation associated with TC genesis in WNP to SST anomalies from different oceanic basins.

\section{Divergent SST evolution trajectories for deficit and excedent TC genesis}

TC genesis in WNP during the TC active season July-October and satisfying the condition of being in the decaying phase of the ten selected El Niño events, varies from -4.6 in 1998 and 2010 to 7.4 in 1992 (Table 1, with 17.4 as the mean number of TC formed each year). The general average of all TC genesis anomalous values gives a small positive figure with no statistical significance although the concurrent NIÑO3.4 index is significantly negative when averaged through the ten events (Table 2). If we use half of the standard deviation (of TC genesis during the whole study period) as a threshold, four events fall into the significant negative group (with deficit TC genesis, referred to as Group1 hereafter), and other four events into the significant positive group (with excedent TC genesis, referred to as Group 2 hereafter). For an intra-group average, both groups (with their negative and positive averages) show high significance at the 95\% confidence level (Table 2). However, their corresponding NIÑO3.4 indices for the simultaneous TC season are very close with negative value, indicating that the most remarkable EI Niño SST warming in the Tropical Central Pacific during the El Niño mature stage is almost totally disappeared. It is clear that the 
NIÑO3.4 area can only exert a feeble impact on TC genesis in the WNP during July-October after El Niño peaks in preceding December.

Let us now examine how SST anomalies evolve in different oceanic basins during the El Niño decaying phase, and for the two groups respectively. Figure 1a shows the three geographic regions where NIÑO3.4 index, the Indian Ocean index, and the North Atlantic tripolar mode index are defined. The evolution of the composite anomalous indices over these regions is depicted in Fig. $1 b$ and $1 c$ for the two sub-groups. For Group 1, we can see that positive NIÑO3.4 index firstly increases, starting from April of the year 0 . It then peaks in December as commonly observed, and gradually decreases thereafter, eventually turns to negative by mid-May. The tropical Indian Ocean starts warming in the El Niño-developing summer. Its peak positive SST anomaly $\left(0.4^{\circ} \mathrm{C}\right)$ occurs in the following March to April, lagging behind the peak of NIÑO3.4 for about three months. The SST anomaly decreases gradually from its peak but still remains positive until October. The lagging of the Indian Ocean SST warming behind the El Niño SST peak has been viewed as the charging effect (Du et al. 2011; Wu et al. 2010; Xie et al. 2009; Yang et al. 2007). The SST anomaly of the North Atlantic tripolar mode index is negative during the developing phase of El Niño, becomes positive after El Niño peaks in December, suggesting that El Niño warms the North Atlantic and its SST index peaks in April. The positive state remains elevated through the following February (Fig. 1b). This suggests that the North Atlantic may also behave as a capacitor for El Niño events in Group 1. The discharging effect through teleconnection into the WNP will be discussed later.

The time evolution of the NIÑO3.4 index for Group 2 (Fig. 1c) is similar to that of Group 1. The SST anomaly over the Indian Ocean, however, has a negligeable value now, kept almost constant from month to month. The North Atlantic tripolar mode is distinctively negative during the developing phase of El Niño, and maintains at a nearzero level with weak positive or negative values in alternance during the following spring and summer. The anomalous SST indices over both the Indian Ocean and North Atlantic remain insignificant from July to October for Group 2 (Fig. 1c, Table 2). It is clear that the NIÑO3.4 SST anomalies in the EI Niño peak winter fail to initiate a relevant teleconnection that could lead to anomalies in the Indian Ocean (warming) and in the North Atlantic (positive tripolar mode). In summary, we can easily conclude that the overall response of the Indian Ocean and North Atlantic shows fundamentally divergent trajectories between the two sub-groups of El Niño events, though the evolution of the NIÑO3.4 index keeps very close.

We now further analyze the spatial pattern of the anomalous SST during the composite life cycle of El Niño for the two sub-groups with opposite effects on the TC genesis in WNP. Group 1 is firstly examined. During the quick El Niño developing phase from September to November, large positive SST anomalies stand out in the central-eastern equatorial Pacific (Fig. 2a). Westerly wind anomalies in the western and central equatorial Pacific tend to weaken the oceanic upwelling and deepen the equatorial thermocline in the eastern Pacific, and thus increase the positive SST anomalies there, decreasing the zonal gradient of SST and thus sea level pressure over 
the equatorial Pacific. These further weaken easterly wind (anomalous westerly enhancement) in the central equatorial Pacific, forming a typical developing El Niño condition through the positive feedback mechanism proposed by Bjerknes (1969). During December-February, El Niño reaches its peak with maximum SST anomalies appearing in the central and eastern equatorial Pacific (Fig. 2c). Anomalous northerlies in the tropical WNP enhance the prevailing northeast trade winds, and thus sea surface evaporation, leading to SST cooling there (Wang et al. 2000). Warm SST anomalies in the central-eastern equatorial Pacific start their weakening course in the spring following the peak (Fig. 2e). This weakening process develops more quickly in the central equatorial Pacific than in the eastern part, turning warm SST anomalies in the former area into cold ones in the summer (Fig. 2g).

Accompanying the El Niño evolution course, SST anomalies in the tropical North Atlantic become slightly warm during the El Niño peak phase (Fig. 2c), and maximize along with small warm (cold) values in mid-high (subtropical) latitudes in March-May during the decaying phase of El Niño (Fig. 2e). The anomalous SST structure in the North Atlantic during this decaying phase resembles the positive North Atlantic tripolar mode (Czaja and Marshall 2001; Yu et al. 2016b). This positive mode, associated with the anomalous cyclonic circulation over the North Atlantic (Fig. 2c and 2e), sustains during summer of the El Niño decaying phase (Fig. $2 \mathrm{~g}$ ).

Similar to the North Atlantic, the Indian Ocean, for Group 1, also shows significant SST anomalies along the EI Niño course, from the developing stage to decaying. The anomalous SST structure in the Indian Ocean shows firstly a dipole-like pattern during the El Niño developing autumn (Fig. 2a), and subsequently develops into a basin-wide warming (Fig. 2c), depicting a typical evolving process for the Indian Ocean's connection with ENSO. The anomalous Walker circulation induces easterly anomalies at surface over the Indian Ocean which are persistent during El Niño (Fig.2a, c, e). The zonal direction of climatological surface winds near the equator over the Indian Ocean changes from easterly into westerly in November-December (Huang and Kinter 2002; Tokinaga and Tanimoto 2004). As a result, a deceleration of wind speed takes place during boreal winter, and leads to SST warming through weakened evaporation. In addition to latent heat flux anomalies, incoming solar radiation anomalies also contribute to the net surface warming during this period. The robust basin-wide warming over the Indian Ocean persists in spring and summer of El Niño decaying phase (Fig. 2e, g).

For Group 2 events, SST anomalies in the North Atlantic show a weak negative tripolar mode during the El Niño peak phase (Fig. 2d). A weak warm SST occurs in the tropical North Atlantic during spring (Fig. 2f), and weakens during summer (Fig. 2h). A robust anomalous positive SST occurs in the Maritime Continent and a positive Pacific meridional mode-like SST pattern (Zhang et al. 2016) does occur over the subtropical northeastern Pacific during summer of the decaying phase (Fig. 2h)

The anomalous easterlies near the equatorial Indian Ocean in Group 2 are much smaller than in Group 1 during the El Niño peak stage (Fig. 2d vs Fig. 2c). In addition, 
the anomalous subsidence associated with the Walker circulation for Group 2 is also weaker than that of Group 1 (not shown). These weak changes in Group 2 lead to a weak basin-wide mode of anomalous SST during the El Niño peak stage (Fig. 2d). Weak SST anomalies persist in the tropical Indian Ocean in the following spring and summer. A careful examination, nevertheless, shows that summer SST anomalies in the Indian Ocean are closer to a weak negative dipole mode (Fig. $2 \mathrm{~h}$ ). It is clear that such SST anomalies are completely negligible compared to the strong all-basin warming observed in Group 1.

\section{How does Teleconnection operate?}

In this section, we attempt to understand why similar El Niño patterns in the tropical Pacific can induce quite divergent SST anomalies in the North Atlantic and Indian Ocean while El Niño decays. Such a difference from these two oceanic basins is believed to modulate the WNP TC genesis. We focus on what happens in spring, just after the mature stage of El Niño, since spring seems a critical period in determining the evolutionary trajectories in the North Atlantic and Indian Ocean (Fig. 1a, Fig. 2e). Let us study firstly the North Atlantic case, which can also modulate the connection of ENSO to the Indian Ocean SST anomalies (Yu et al. 2016a). Previous studies suggested that the spring SST warming over the tropical North Atlantic is associated with evaporation reduction and incoming solar radiation enhancement at the surface (Alexander et al. 2002; García-Serrano et al. 2017). In addition, local SST anomalies in the preceding winter season also matters for the subsequent SST evolution in the tropical North Atlantic (Taschetto et al. 2016). With a simple consideration of different terms entering into the energy budget equation, we can see that the incremental SST anomalies from winter (Fig.2C) to spring (Fig. 2e) should be proportional to the accumulated atmospheric forcing during that time interval. The anomalous southwesterlies, taking place in Group 1 and lying in the south of an anomalous cyclonic circulation in the mid-latitude North Atlantic, can decrease the climatologic northeastern flow, and thus diminish evaporation (Fig.3a), leading to spring SST warming in the tropical North Atlantic. The anomalous subsidence over the tropical North Atlantic, related to the eastward-shifted Walker circulation (not shown), reduces clouds, increases solar radiation (Fig.3b), and favors SST warming as shown in Fig. 2e. We believe that this physical interaction is an important issue and a key to understand remote effects from El Niño teleconnection.

Generally speaking, wind anomalies can lead anomalous heat fluxes for about one month. Fig. 4 shows composite anomalies of 500-hPa geopotential height and 850$\mathrm{hPa}$ wind vectors for January-March (just after the El Niño peak), for Group 1 and Group 2, respectively. The atmospheric circulation anomalies mainly present a quasigeostrophic structure. Figure 4a clearly shows a wave-train (high-low-high-low geopotential height anomalies) at $500 \mathrm{hPa}$, emanating from the tropical Pacific to the sub-tropical North Atlantic. This is a typical Pacific North America teleconnection pattern (Wallace and Gutzler 1981). The most robust anomalous geopotential low, situated over the eastern North Pacific, deepens further the Aleutian low. The other two subtropical centers of low geopotential height occur over Central America and 
over the subtropical North Atlantic. Over the Atlantic, the dipolar geopotential height anomaly at high latitudes is reminiscent of a negative North Atlantic Oscillation (NAO, Czaja and Marshall 2001)- like atmospheric circulation. This geopotential height anomaly and its associated anomalous cyclonic circulation incline to weaken the subtropical high, reducing the surface northeast trade winds from winter to spring (Fig. 4a), and diminishes the evaporative cooling at the surface (Fig. 3a).

For Group 2, the low geopotential height over Central America is much weaker and does not extend into the North Atlantic (Fig. 4b). A significant positive anomaly of geopotential height occurs over the mid-latitude North Atlantic between $25^{\circ} \mathrm{N}$ and $40^{\circ} \mathrm{N}$. The dipolar structure over the extratropical North Atlantic is out of phase, compared to Group 1. Czaja and Marshall (2001) already suggested that a negative NAO dipolar pattern tends to generate a positive North Atlantic tripolar mode in SST, as we find in Group 1. The presence of the positive phase of the NAO dipolar pattern in Group 2 is consequently unfavorable for the generation of the tripolar SST anomalies in the North Atlantic. Clearly, whether an El Niño can force a remote negative NAOlike atmospheric circulation pattern over the extratropical North Atlantic is a key issue to determine if a positive North Atlantic SST tripolar mode occurs in spring following an El Niño peak.

We also believe that, in Group 1, the coupling effect between North Atlantic SST and NAO makes the positive North Atlantic SST tripolar mode maintaining until October. Yu et al. (2016a, b) argued that this North Atlantic SST tripolar mode inclines to reduce TC genesis over the WNP through forcing an anticyclonic circulation there with the help of a relay effect by the Indian Ocean. Actually, the tropical North Atlantic SST warming, through a Gill-type response (Gill 1980) in the atmosphere, leads to anomalous low-level easterlies over the tropical Indian Ocean. The anomalous easterlies decrease the climatological westerly winds over the north Indian Ocean, diminishing the evaporative cooling and ultimately warming the sea surface there about one month later. Warmer SST in the north tropical Indian Ocean further enhances local convection, inducing anomalous north-easterlies, and thus enhances anticyclonic vorticity over the WNP monsoon trough region through the Kelvin waveinduced Ekman divergence mechanism (Xie. et al. 2009).

In summary, El Niño in Group 1 seems able to remotely initiate a negative NAOlike atmospheric circulation pattern over the North Atlantic while El Niño in Group 2 fails to do it. This is a key issue in our working hypothesis, since the NAO-like atmospheric circulation would ultimately imprint the signal from El Niño into SST in the North Atlantic. In the following, we attempt to understand the relevant physical process responsible for the divergence between the two sub-groups by making a diagnostic on the propagation of Rossby waves.

The wave-activity flux is a useful diagnostic tool for the Rossby wave energy propagation under the quasi-geostrophic circumstances (Takaya and Nakamura 2001). It represents a "snapshot" of a propagating packet of stationary or migratory quasigeostrophic Rossby wave disturbances and thereby for inferring locations of emission 
and absorption. We now examine the $300-\mathrm{hPa}$ zonal winds and wave activity fluxes. Fig. 5a displays the long-term climatology and Fig. 5b-c the anomalous fields corresponding to the two sub-groups of El Niño events. Fig. 5 a clearly shows the jet stream cores over the North Pacific and North Atlantic. We can also see westerly winds over the central-eastern equatorial Pacific, which constitutes a favorable window for tropical perturbations to propagate to extratropical regions (Wen et al., 2019). In Fig. $5 b$ displaying anomalous fields for Group 1, we can see that anomalous westerlies occur over the subtropical North Pacific (the exit region of the East Asian jet stream) and over Central America with extension to the North Atlantic. These two regions constitute the key pathways for Rossby waves to propagate energy (originated in latent heat release) from the tropics to extra-tropics, as clearly depicted by the wave activity fluxes. The northward propagating pathway is tightly related to the Pacific North America pattern (Fig. 5b) with downstream extension to the North Atlantic. This leads to low geopotential height over the central-eastern North Pacific with strong anomalies centering near $150^{\circ} \mathrm{W}, 45^{\circ} \mathrm{N}$, but high geopotential height over North America as exhibited in Fig. 4a. The northeastward pathway starting from the eastern tropical Pacific $\left(120^{\circ}-80^{\circ} \mathrm{W}\right)$ through Central America allows energy to propagate from the tropics to the subtropical North Atlantic, and to propagate further through the subtropical jet playing the role of a wave guide (Hoskins and Ambrizzi 1993; Graf and Zanchettin 2012). This allows to produce geopotential lows centered near $90^{\circ} \mathrm{W}, 30^{\circ}$ $\mathrm{N}$, and $40^{\circ} \mathrm{W}, 30^{\circ} \mathrm{N}$, as shown in Fig. 4 a.

For Group 2 (Fig. 5c), enhanced precipitation can be seen over the equator between $180^{\circ}$ and $150^{\circ} \mathrm{W}$ during Jan-Mar. The center of the anomalies is westward shifted, compared to Group 1. The anomalous westerlies over the eastern North Pacific are much weaker than their counterpart in Group 1. Such a situation is favorable for Rossby waves to dissipate energy preferentially through the west pathway over the North Pacific, lowering geopotential height over the eastern North Pacific, as shown in Fig. 5b. Weaker anomalies of zonal wind along the $30^{\circ} \mathrm{N}$ over Central America are not favorable for waves to propagate into the subtropical North Atlantic. Eastward wave propagation is found over the tropical eastern North Atlantic (Fig.5c), indicating that the tropical North Atlantic may also be a source of Rossby wave energy. The atmospheric response over the Atlantic to heating perturbations from the centraleastern equatorial Pacific in Group 2 is generally much weaker than that in Group 1. By consequence, spring SST anomalies over the North Atlantic tend to be more dependent of SST from the preceding season (winter). Local coupling between ocean and atmosphere should play a more independent role in the North Atlantic sector in the configuration of Group 2.

\section{Influences of basin-scale SST anomalies on TC genesis}

\subsection{Factorial analysis of TC genesis}

TC genesis is closely associated with its local dynamic and thermodynamic conditions (Emanuel and Nolan 2004), including absolute vorticity at $850 \mathrm{hPa}$, relative humidity at $700 \mathrm{hPa}$, vertical wind shear between $850 \mathrm{hPa}$ and $200 \mathrm{hPa}$ and maximum 
potential intensity at sea surface. Their suggested theoretical-empirical formular has been widely used in studying the mechanism of TC genesis and variability over multibasins (Camargo et al. 2007, Yu et al. 2016a). Figure 6 shows composite anomalies of a few environmental parameters and circulation patterns during July-October for both Group 1 and Group2, based on reanalysis data. In the region with significant low TC genesis for Group 1 over the central-eastern WNP (yellow box in Figs. a, c, e), composite relative vorticity and relative humidity show mostly negative values (Figs. $6 \mathrm{a}, \mathrm{c}$ ), and the vertical wind shear is mostly positive (Fig. 6e), which constitutes an unfavorable configuration for TC genesis. More closely, we can observe that an anomalous anticyclonic circulation occurs over a wide scope of the WNP with a center situated in the central WNP (Fig. 6a). Robust anomalous easterlies appear to the south of $20^{\circ} \mathrm{N}$. They contribute to maintain low relative humidity at $600 \mathrm{hPa}$ (Fig. 6c), by actually transporting climatologically-low humidity air mass westward into the centraleastern tropical WNP. The maximum potential intensity (related to local SST) shows, however, little impact. This large-scale environment, unfavorable for TC genesis, is actually associated with remote forcing procured by SST anomalies from the Indian Ocean and North Atlantic which are somehow inheritors of El Niño in the tropical Pacific.

Group 2 regroups cases with excedent TC genesis. The most active areas are mainly found in the southwestern WNP, namely in the South China Sea and near the Philippines (Fig. 6b). These regions present an anomalous cyclonic circulation with mostly enhanced relative vorticity and relative humidity (Fig. $6 \mathrm{~d}$ ). Fig. $6 \mathrm{f}$ shows that the anomalous vertical wind shear is weakly positive. There is thus a negligible but inhibiting effect by vertical wind shear on the TC genesis increase for Group 2. Major contributors are attributable to enhanced vorticity and humidity. The anomalous cyclonic circulation over the southwestern part of WNP is consistent with the main precipitation intensification area (northeast side) of the Maritime Continent. It looks like a westward-propagated Rossby wave excited by the latent heat release, reminiscent of a Gill-type response (Gill 1980) to warm SST anomalies over the Maritime Continent.

\subsection{Sensitivity experiment with a climate model}

To identify and confirm the relationship between the atmospheric conditions as shown in Fig. 6 and SST anomalies distributed in different oceanic basins, we conducted two sets of sensitivity experiment using ECHAM6.3 with surface forcing from SST anomalies previously-identified for Group 1 and Group 2, respectively. Each set comprises 30 independent members realized with different initial states as described in the Method section. In the first set of sensitivity simulations, the SST anomalies from both the North Atlantic and the Indian Ocean areas in Group 1 (Fig. 7 a-d) are used as surface forcing. Similarly, the second set of simulations use the SST anomalies from the Maritime Continent (Fig. 7 e-h) in Group 2. The two sets of sensitivity experiment are to be contrasted with the control experiment comprising equally 30 members realized under the same conditions but with climatological SST. 
When SST anomalies from both the North Atlantic and Indian Ocean are added as an external forcing, the overall atmospheric response shows an anomalous anticyclonic circulation over most of the WNP region with robust anomalous easterlies to the south of $20^{\circ} \mathrm{N}$ (Fig. 8a). One of the anticyclonic centers is located in the central part of WNP near $145^{\circ} \mathrm{E}, 20^{\circ} \mathrm{N}$, which is close to the observed one shown in Fig. $6 \mathrm{a}$, although the anomalous anti-cyclonic circulation in the model shows a slightly northward bias. This leads to decreases of vorticity and humidity over the southern region where TC genesis decreases (Fig. 8a, c VS Fig. 6a, c). The increase of vertical wind shear in the region of TC genesis reduction is not significant. In short, the simulated circulation and factors over the WNP are mostly similar to the observed results (Fig.8 VS Fig. 6), indicating that the observed anomalous anticyclonic circulation and factors shown in Figs. 6a, c, e are attributable to the North Atlantic and Indian Ocean SST anomalies. As outlined above, the second set of sensitivity experiment was designed in the same way as the first one, except that the Maritime Continent SST anomalies, rather than those from the North Atlantic and Indian Ocean, were superimposed into the observed climatological SST. Model output (sensitivity simulation minus control simulation) clearly shows positive anomalous relative vorticity accompanying an anomalous cyclonic circulation (Fig. 8b) and enhanced relative humidity (Fig. 8d) over the southwestern WNP. This model result resembles its observational counterpart shown in Figs. $6 \mathrm{~b}, \mathrm{~d}$. The atmospheric response, in terms of atmospheric circulation and humidity, favors the TC genesis over the South China Sea and around the Philippines. The model sensitivity runs confirm that the anomalous cyclonic circulation along with positive relative vorticity and humidity over the South China Sea and the Philippines, as shown in Fig. 6 b, d, f, is an atmospheric response to the latent heat release associated with the positive SST anomalies from the Maritime Continent.

\section{Conclusions and Discussions}

Tropical cyclones (TC) formed in the Western North Pacific (WNP) can have strong impacts on Southeast Asian countries and societies. It is of high relevance to study TC genesis in this region and to investigate the associated atmospheric conditions allowing its forecasting at seasonal scale. For this regard, El Niño provides an expected signal for predicting TC genesis in its active season following the peak of El Niño. However, this El Niño signal is ambiguous since both deficit and excedent activities of TC genesis are actually observed after El Niño occurs. Our study presented here was dedicated to the investigation of plausible physical mechanisms conducting to divergent TC genesis after El Niño peaks. For this purpose, we selected 10 El Niño events encountered during 1970-2016. They are then stratified into two sub-groups with reduced TC genesis (Group 1) and enhanced TC genesis (Group 2) in the TC active season from July to October while El Niño decays in the WNP. Our main approach was the diagnose of observation data and re-analysis within the composite framework to extract common features inside each sub-group. We also used a few numerical sensitivity simulations produced with a global climate model to investigate underlying physical mechanisms. Various SST anomalies and atmospheric circulation responses to 
El Niño events were investigated for each group.

For Group 2, the spring SST anomalies over both the Indian Ocean and North Atlantic are weak and sporadic, very different from Group 1. Actually, significant warm SST anomalies from winter to spring was observed over the tropical and high-latitude North Atlantic and over the tropical Indian Ocean in Group 1, while robust warm SST occurs over the Maritime Continent in summer in Group 2.

Our work confirms the conclusion of previous studies and shows that warm SST anomalies occurring in the tropical North Atlantic are generally associated with a decrease of evaporation and enhanced incoming solar radiation at the sea surface. The reduction of evaporative cooling over the tropical North Atlantic essentially results from weakened trade winds during early spring for Group 1 . We can conclude that for Group 1, SST anomalies over the North Atlantic and Indian Ocean from winter to spring are mainly connected to remote atmospheric forcing, whereas for Group 2, it is also largely determined by local interactions between atmosphere and ocean.

Although a typical high-low-high geopotential height pattern occurs in late winter for the two groups, significant differences exist between them. Positive (negative) geopotential height anomalies are found in the high-latitude (subtropical) North Atlantic for Group 1, leading to a negative NAO-like circulation, but for Group 2, positive geopotential height anomalies occur in the subtropical North Atlantic with a positive NAO-like circulation over the extratropical North Atlantic. The salient difference of atmospheric circulation over the extratropical North Atlantic for the two groups seems to be a consequence of different ways that teleconnection operates from the equatorial Pacific to North Atlantic.

Our results suggest that the response of atmospheric circulation at upper troposphere over the extratropical North Atlantic depends not only on the intensity and position of anomalous precipitation over the equatorial Pacific but also on the mean structure of zonal wind over the tropical Pacific, extratropical North Pacific and Atlantic. The faint teleconnection from the tropical Pacific to extratropical North Atlantic in Group 2 is believed to be associated with smaller precipitation anomalies over the equatorial Pacific and with weakened zonal westerlies along $30^{\circ} \mathrm{N}$. This situation tends to suppress the Rossby wave energy's meridional propagation from the eastern tropical Pacific to subtropical latitudes. As a result, only weak anomalous negative geopotential height is induced to Central America and a weak positive NAOlike circulation over the extratropical North Atlantic.

The composite analyses and model sensitivity experiments allow us to conclude that the anomalous easterlies over the southern WNP along with negative anomalous relative vorticity and relative humidity, and positive anomalous vertical wind shear (all tending to lower TC genesis) are modulated by Indian Ocean warming and a positive North Atlantic tripolar mode for Group 1. The anomalous cyclonic circulation with positive relative vorticity and humidity (tending to enhance TC genesis in the South China Sea and around the Philippines) are influenced by warm SST over the Maritime Continent for Group 2. 
Our study shows clearly that TC genesis over the Western North Pacific during EI Niño decaying phase is highly variable, largely dependent of El Niño-induced SST evolutions in other oceanic basins, in particular, in the North Atlantic and Indian Ocean. A simple schematic can be drawn to summarize our main findings and to depict how different TC genesis is operating for the two groups of El Niño events (Fig. 9). Given the summer SST anomaly over the Indian Ocean is closely associated with the precedingseason SST anomalies over the North Atlantic (Yu et al. 2016a), the weak response of SST over the Indian Ocean in Group 2 may be related to the feeble SST response over the North Atlantic. The seasonal-mean zonal wind over the tropical Pacific and subtropical latitudes plays an important role in teleconnection pathways linking the atmospheric heating over the central-eastern equatorial Pacific to the North Atlantic. Yu et al. (2020) suggested that the weak westerly anomaly over Central America and the subtropical North Atlantic during 2015-2016 El Niño event is associated with the subtropical North Pacific warming. The warming reduces the El Niño-created meridional thermal gradient and then the anomalous westerlies, which constitutes a less favorable situation for tropical perturbations to efficiently dissipate to higher latitudes through Rossby wave trains. It would be interesting, in future works, to check whether other events in Group 2 show the same behavior. Finally, we need to formulate a precautionary remark on our results which were deduced from a small size of samples, with only $10 \mathrm{El} \mathrm{Nino} \mathrm{events} \mathrm{identified,} \mathrm{although} \mathrm{we} \mathrm{paid} \mathrm{the} \mathrm{necessary}$ attention in dealing with issues on uncertainty and statistical significance during our investigation. This is due to the lack of reliable TC data beyond the satellite-observation era.

Acknowledgments: Two anonymous reviewers are acknowledged for their constructive and helpful comments on an earlier version of the manuscript. We also thank Prof. Liang X. and Dr. Melinda Peng for their comments and assistance in editing the manuscript. This work was supported by the National Key R\&D Program of China (2018YFC1506002, 2018YFC1507704) and the National Natural Science Foundation of China Grant $(41575083,41730961)$. The atmospheric circulation reanalysis, surface precipitation and Niño3.4 data were retrieved from http://www.esrl.noaa.gov/psd/. The tropical cyclone track data were obtained from https://metoc.ndbc.noaa.gov/web/guest/itwc/best-tracks, and the SST data from https://climatedataguide.ucar.edu/climate-data/ sst-data-hadisst-v11. The model simulations were conducted in the High Performance Computing Center of Nanjing University of Information Science \& Technology

\section{References}

Alexander MA, Blade I, Newman M et al. 2002. The Atmospheric Bridge: The Influence of ENSO Teleconnections on Air-Sea Interaction over the Global Oceans. J. Clim. 15: 2205-2231.

Bjerknes J. 1969. Atmospheric teleconnections from the equatorial Pacific. Mon. Wea. Rev. 97: 163-172.

Camargo SJ, Emanuel KA, Sobel AH. 2007. Use of a genesis potential index to 
diagnose ENSO effects on tropical cyclone genesis. J. Clim. 20: 4819-4834.

Czaja A, Marshall J. 2001. Observations of atmosphere-ocean coupling in the North Atlantic. Q. J. R. Meteorol. Soc. 127: 1893-1916.

Czaja A, Vaart VD, Marshall J. 2002. A diagnostic study of the role of remote forcing in tropical Atlantic variability. J. Clim. 15: 3280-3290.

Chen G, Wang K. 2018. Why is the Tropical Cyclone Activity over the Western North Pacific so Distinct in 2016 and 1998 Following Super El Niño Events? J. Meteorol. Soc. Japan. Ser. II. 96: 97-110.

Chia HH, Ropelewski CF. 2002. The interannual variability in the genesis location of tropical cyclones in the northwest Pacific. J. Clim. 15: 2934-2944.

Du Y, Yang L, Xie SP. 2011. Tropical Indian Ocean influence on northwest Pacific tropical cyclones in summer following strong El Niño. J. Clim. 24: 315-322.

Emanuel KA, Nolan DS. 2004. Tropical cyclone activity and global climate. Amer Meteor Soc 240-241. Reprints, 26th Conference on Hurricanes and Tropical Meteorology, Miami, FL.

Enfield DB, Mayer DA. 1997. Tropical Atlantic SST variability and its relation to El NiñoSouthern Oscillation. J. Geophys. Res. 102: 929-945.

Franklin JL, Mcadie CJ, Lawrence MB. 2003. Trends in track forecasting for tropical cyclones threatening the United States, 1970-2001, BAMS,1196-1203.

García-Serrano J, Cassou C, Douville H et al. 2017. Revisiting the ENSO Teleconnection to the Tropical North Atlantic. J. Clim. 30: 6945-6957.

Giannini A, Chiang JCH, Cane MA et al. 2001. The ENSO Teleconnection to the Tropical Atlantic Ocean: Contributions of the Remote and Local SSTs to Rainfall Variability in the Tropical Americas. J. Clim. 14: 4530-4544.

Gill AE. 1980. Some simple solutions for heat-induced tropical circulation. Q. J. $R$. Meteorol. Soc. 106: 447-462.

Graf HF, Zanchettin D. 2012. Central Pacific El Niño, the "subtropical bridge" , and Eurasian climate. J. Geophys. Res. 117: D01102.

Han, Z, Luo F, and Wan J. 2016. The observational influence of the North Atlantic SST tripolar on the early spring atmospheric circulation. Geophys. Res. Lett. 43: 29983003.

Hoskins BJ, Ambrizzi T. 1993. Rossby wave propagation on a realistic longitudinally varying flow. J. Atmos. Sci. 50: 1661-1671.

Huang B, Kinter JL. 2002. Interannual variability in the tropical Indian Ocean. J Geophys Res: Oceans 107: 20-1-20-26. 
Huo L, Guo P, Hameed S et al. 2015. The role of tropical Atlantic SST anomalies in modulating western North Pacific tropical cyclone genesis. Geophys. Res. Let. 42: $2378-2384$.

Kalnay E, Kanamitsu M, Kistler R, et al. 1996. The NECP/NCAR 40-year reanalysis project. Bull. Am. Meteorol. Soc. 77: 437-471.

Klein SA, Soden BJ, Lau N-C. 1999. Remote sea surface temperature variations during ENSO: Evidence for a tropical atmospheric bridge. J. Clim. 12: 917-932.

Krishnamurthy L, Vecchi GA, Msadek R, Murakami H, Wittenberg A, Zeng F. 2016. Impact of Strong ENSO on Regional Tropical Cyclone Activity in a HighResolution Climate Model in the North Pacific and North Atlantic Oceans. J. Clim. 29: 2375-2394.

Lau NC, Nath MJ. 2001. Impact of ENSO on SST variability in the North Pacific and North Atlantic: Seasonal dependence and role of extratropical air-sea coupling. J. Clim. 14: 2846-2866.

Li T. 2012. Synoptic and climatic aspects of tropical cyclogenesis in Western North Pacific. Nova Science Publishers, Inc. Oouchi K, Fudeyasu H(eds) Chap. 3: pp.6194.

Li T, Wang B, Wu B et al. 2017. Theories on Formation of an Anomalous Anticyclone in Western North Pacific during El Niño: A Review. J. Meteorol. Res. 31: 987-1006.

Lintner BR, Chiang JCH. 2007. Adjustment of the remote tropical climate to El Niño conditions. J. Clim. 20: 2544-2557.

Rayner NA, Parker DE, Horton EB et al. 2003. Global analyses of SST, sea ice and night marine air temperature since the late nineteenth century. J. Geophys. Res. 108: 4407. doi:10.1029/2002JD002670.

Saravanan R, Chang P. 2000. Interaction between tropical Atlantic variability and El Niño-Southern Oscillation. J. Clim. 13: 2177-2194.

Stevens B, Giorgetta M, Esch M et al. 2015. Atmospheric componenet of the MPI-M Earth System Model: ECHAM6, J. Adv. Model. Earth. Syst. 5: 146-172.

Takaya K and Nakamura H. 2001. A formulation of a phase-independent waveactivity flux for stationary and migratory quasigeostrophic eddies on a zonally varying basic flow J. Atmos. Sci. 58 608-627.

Taschetto AS, Meehl GA, Mcgregor S. 2016. How sensitivity are the Pacific-tropical North Atlantic teleconnections to the position and intensity of El Niño-related warming. Clim. Dyn. 46: 1841-1860.

Tokinaga $\mathrm{H}$, Tanimoto Y. 2004. Seasonal transition of SST anomalies in the tropical Indian Ocean during EI Niño and Indian Ocean dipole years. J. Meteorol. Soc. Japan. Ser. I/ 82: 1007-1018. 
Trenberth KE. 1997. The definition of El Niño. BAMS. 78: 2771-2778.

Vecchi GA, Harrison DE. 2006. The termination of the 1997-98 El Niño. Part I: Mechanisms of oceanic change. J. Clim. 19: 2633-2646.

Wallace JM, Gutzler DS. 1981. Teleconnections in the geopotential height field during the northern hemisphere winter. Monthly. Weather. Review. 109: 784812.

Wang B, Wu R, Fu X. 2000. Pacific-East Asian Teleconnection: How Does ENSO Affect East Asian Climate? J. Clim. 13: 1517-1536.

Wang B, Chan JCL. 2002. How Strong ENSO Events Affect Tropical Storm Activity over the Western North Pacific. J. Clim. 15: 1643-1658.

Wang B, Li J, He Qiong. 2017. Variable and robust East Asian monsoon rainfall response to El Niño over the past 60 years. 1957-2016. Adv. Atmos. Sci. 34: 1235-1248.

Wang B, Zhang Q. 2002. Pacific-East Asian teleconnection. Part II: How the Philippine Sea anomalous anticyclone is established during the El Niño development. J. Clim. 15: 3252-3265.

Webster PJ, Moore AM, Loschnig JP, Leben RR. 1999. Coupled ocean- atmosphere dynamics in the Indian Ocean during 1997-98. Nature. 401: 356-360.

Wen, N, Liu, Z, Li, L. 2019. Direct ENSO impact on East Asian summer precipitation in the developing summer. Clim. Dyn. 52: 6799-6815.

Wu B, Li T, Zhou T. 2010. Relative contributions of the Indian Ocean and local SST anomalies to the maintenance of the western North Pacific anomalous anticyclone during El Niño decaying summer. J. Clim. 23: 2974-2986.

Wu L, Feng H, Liu Z et al. 2007. Atmospheric Teleconnections of Tropical Atlantic Variability: Interhemispheric, Tropical-Extratropical, and Cross-Basin Interactions. J. Clim. 20: 856-870.

Wu YK, Hong CC, Chen CT. 2018. Distinct Effects of the Two Strong El Niño Events in 2015-2016 and 1997-1998 on the Western North Pacific Monsoon and Tropical Cyclone Activity: Role of Subtropical Eastern North Pacific Warm SSTA. J. Geophys. Res: Oceans 123: 3603-3618.

Xie SP, Hu K, Hafner J et al. 2009. Indian Ocean Capacitor Effect on Indo-Western Pacific Climate during the summer following El Niño. J. Clim. 22: 730-747.

Yang J, Liu Q, Xie S-P et al. 2007. Impact of the Indian Ocean SST basin mode on the Asian summer monsoon. Geophys. Res. Let. 34: L02708.

Yeh S W, Cai W et al. 2018. ENSO atmospheric teleconnections and their response to greenhouse gas forcing. Rev. Geophys. 56: 185-206.

Yu JH, Li T, Tan ZM et al. 2016a. Effects of tropical North Atlantic SST on tropical 
cyclone genesis in the western North Pacific. Clim. Dyn. 46: 865-877.

Yu JH, Chen C, Li T et al. 2016b. Contribution of major SSTA modes to the climate variability of tropical cyclone genesis frequency over the western North Pacific. Q. J. R. Meteorol. Soc. 142: 1171-1181.

Yu JH, Zhang X, Li L et al. 2020. Salient difference of sea surface temperature over the North Atlantic in the spring following three super El Niño events. Environ. Res. Lett. 15: 094040.

Zhan R, Wang Y, Liu Q. 2017. Salient differences in tropical cyclone activity over the western North Pacific between 1998 and 2016. J. Clim. 30: 9979-9997.

Zhan R, Wang Y, Tao L. 2014. Intensified Impact of East Indian Ocean SST Anomaly on Tropical Cyclone Genesis Frequency over the Western North Pacific. J. Clim. 27: 8724-8739.

Zhang W, Vecchi GA and Murakami H et al. 2016. The Pacific Meridional Mode and the Occurrence of Tropical Cyclones in the Western North Pacific. J. Clim. 29: 381-398. 
Table 1 Deviation from long-term climatology for NIÑO3.4 index in the Central Equatorial Pacific and TC genesis in the WNP during the TC active season (from July to October) after El Niño peaks in the preceding December.

\begin{tabular}{lll}
\hline year & $\begin{array}{l}\text { NINO3.4 index } \\
\text { Anomaly }\end{array}$ & $\begin{array}{l}\text { TC } \\
\text { anomaly }\end{array}$ \\
\hline 1973 & -1.2 & 0.4 \\
1978 & -0.4 & 2.4 \\
1983 & -0.3 & -1.6 \\
1988 & -1.5 & 0.4 \\
1992 & -0.1 & 7.4 \\
1995 & -0.4 & 2.5 \\
1998 & -0.9 & -4.6 \\
2003 & 0.2 & -3.6 \\
2010 & -1.4 & -4.6 \\
2016 & -0.6 & 4.4 \\
\hline
\end{tabular}


Table 2 Intra-group average, corresponding to the two distinct groups (identified by different activities of TC genesis, Group 1 being of reduced TC genesis, and Group 2 enhanced TC genesis), for different anomalies of variables or parameters, including NIÑO3.4 index from January to March and from July to October, TC genesis, Indian Ocean index and North Atlantic index in July-October. The one (two) star means 90 (95) \% confidence level by two-sided student' T- test.

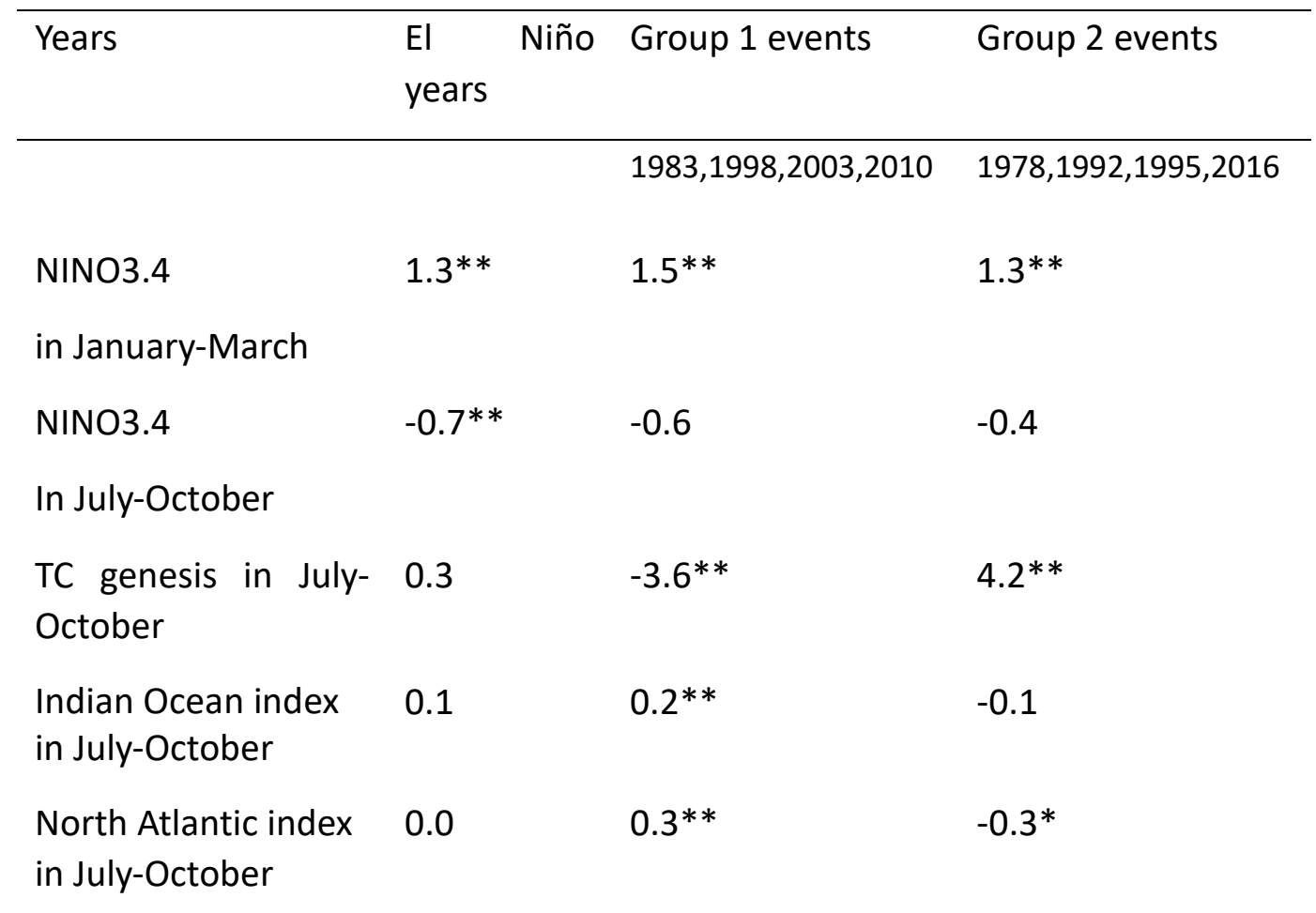



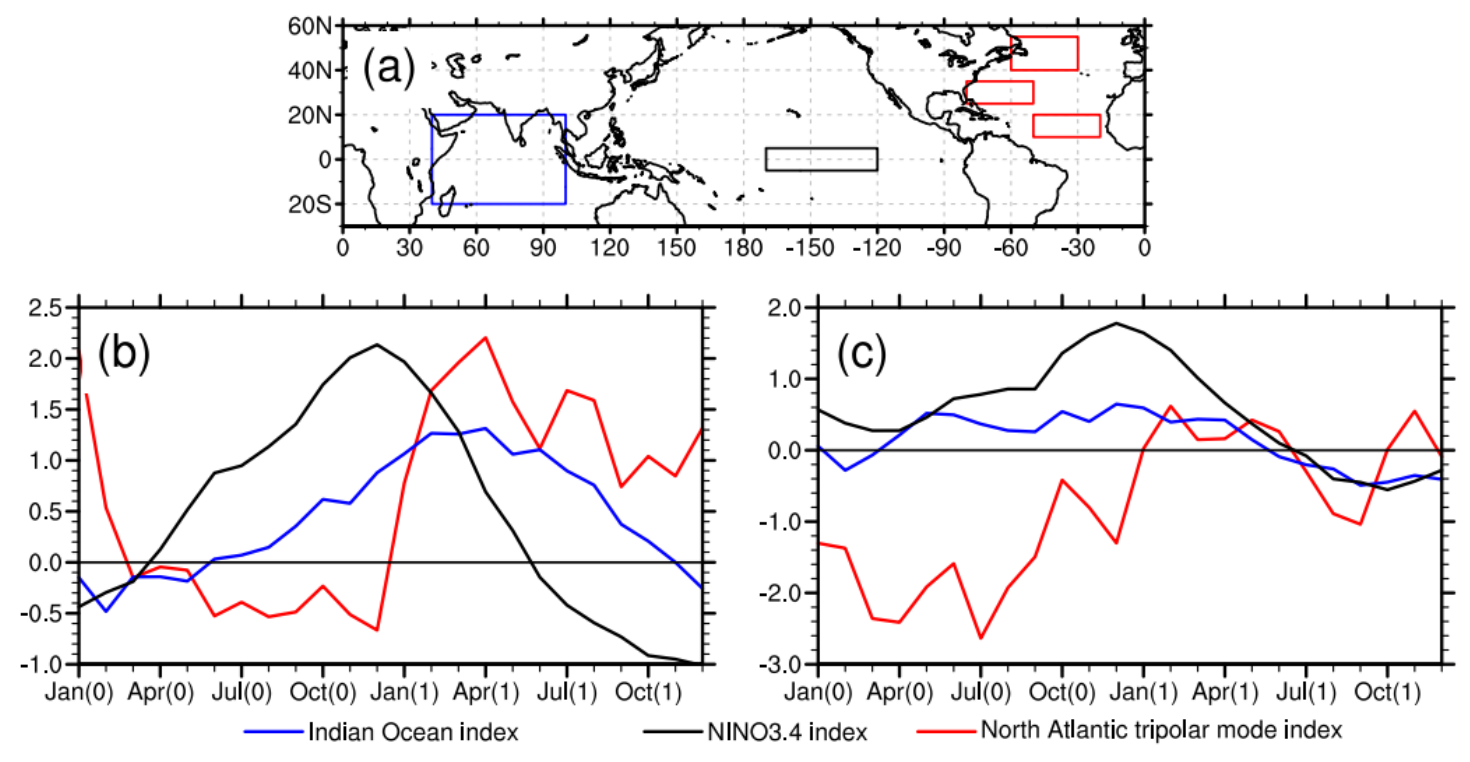

Figure 1. (a) Geographic locations of the three indices to measure SST evolutions in three oceanic basins, NIÑO3.4 index $\left(5^{\circ} \mathrm{S}-5^{\circ} \mathrm{N}, 170^{\circ}-120^{\circ} \mathrm{W}\right.$, black square), tropical Indian Ocean index $\left(20^{\circ} \mathrm{S}-20^{\circ} \mathrm{N}, 40^{\circ}-100^{\circ} \mathrm{E}\right.$, blue square) and North Atlantic tripolar mode index (red squares). (b) Temporal evolution of the three indices corresponding to a composite El Niño event in Group1, standardized anomalous NIÑO3.4 index (black line), anomalous sea surface temperatures averaged in the tropical Indian Ocean (blue line), the North Atlantic tripolar mode index (red line). (c) The same as in Panel b, but for Group 2. Numbers in parentheses denote years relative to the El Niño events: 0 represents a developing year and 1 represents a decay year. 


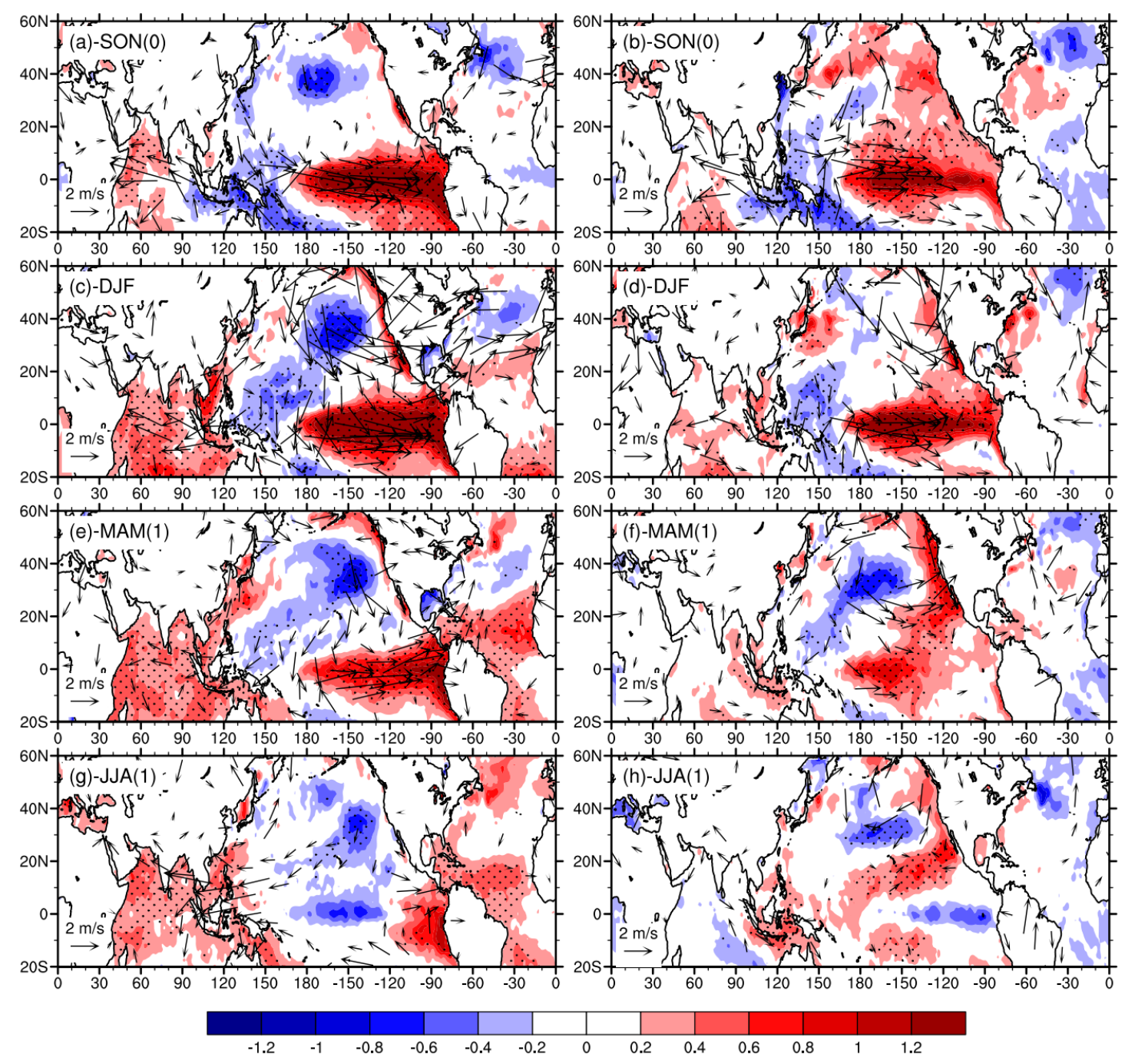

Figure 2. Anomalous SST (shading, unit: ${ }^{\circ} \mathrm{C}$ ) and wind vector at $850 \mathrm{hPa}$ (unit: $\mathrm{m} \mathrm{s}^{-1}$ ) for a composite El Niño event inside each sub-group (Group 1 on the left, Group 2 on the right). From top to bottom are, respectively, the developing phase in SeptemberNovember $(a, b)$, the peak phase in December-February $(c, d)$, the decaying phase in March-May (e, f) and the post-El Niño phase in June-August $(g, h)$. Stippling represents SST anomalies exceeding the $95 \%$ confidence level, and only wind anomalies above the $95 \%$ confidence level are shown as vectors. 


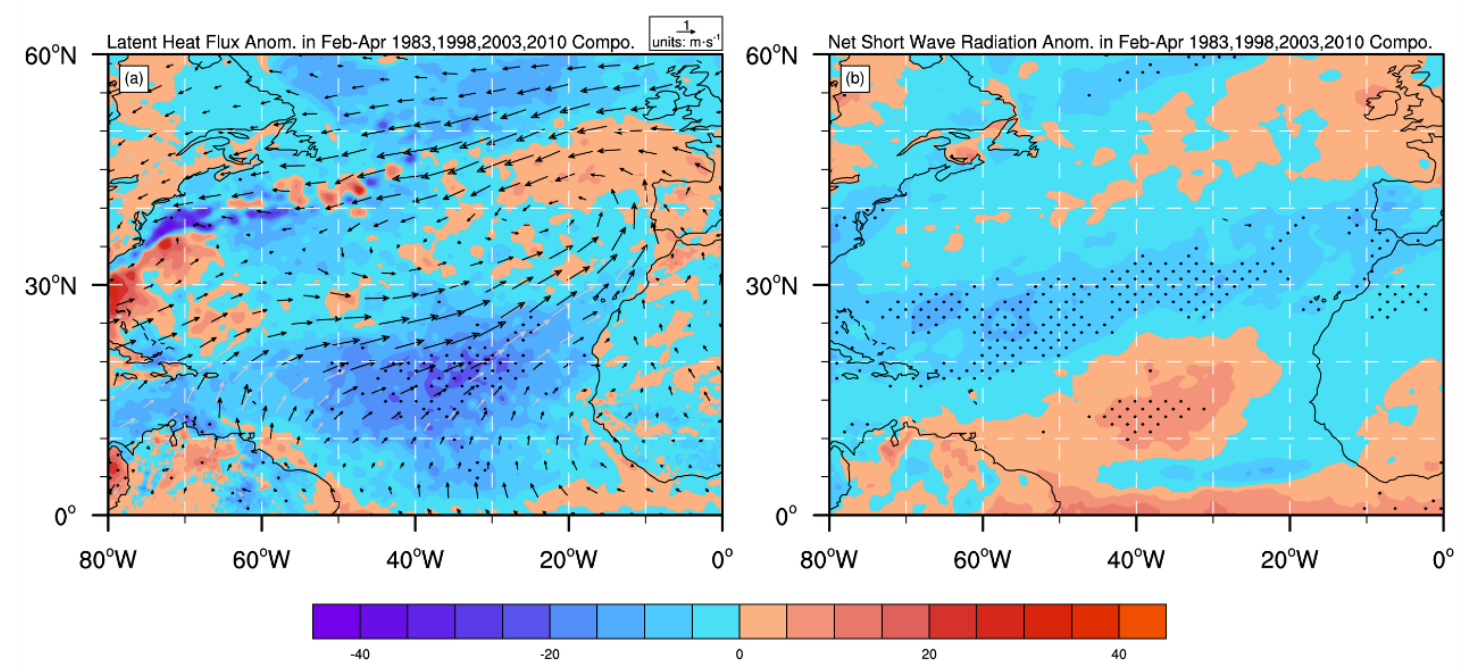

Figure 3 (a) Anomalous latent heat flux (shading, positive upward, unit: $\mathrm{W} \mathrm{m-2}$ ) and wind vector (unit: $\mathrm{m} \mathrm{s}-1$, plotted when the $95 \%$ confidence level reached) over the North Atlantic during the decaying phase in spring from Feb to Apr for the composite El Niño event in Group 1. (b) The same as in Panel a, but for net short-wave radiation at surface (positive downward). The stippling represents the shading exceeding the $95 \%$ confidence level 


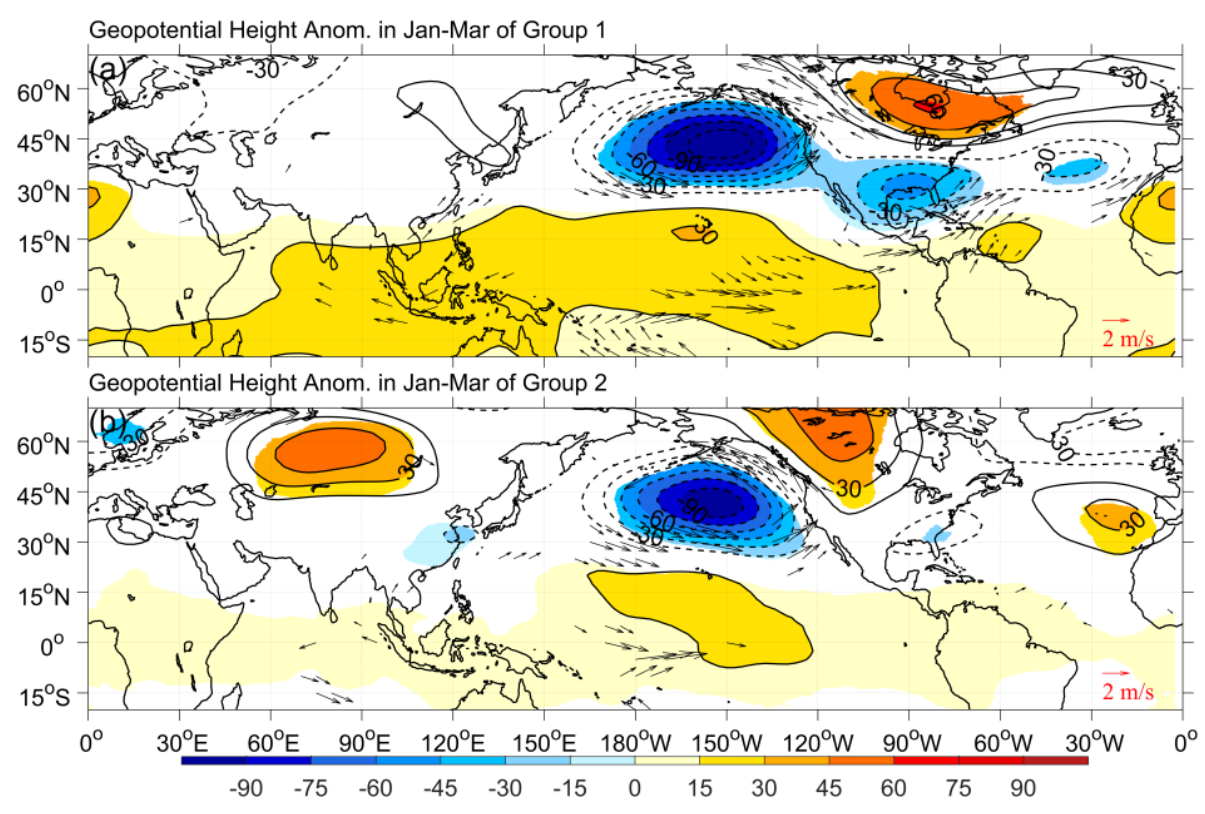

Figure 4. Anomalous fields of $500-\mathrm{hPa}$ geopotential height (contour, the solid is for positive anomaly and the dashed is for negative one, the interval is $15 \mathrm{gpm}$ ) and 850hPa wind vector (unit: $\mathrm{m} \mathrm{s}^{-1}$ ) in Jan to Mar after the peak of the composite El Niño in Group 1 (panel a) and Group 2 (panel b). Shading indicates the significance of contour exceeding $95 \%$ confidence level and only wind anomalies above the $95 \%$ confidence level are shown. 


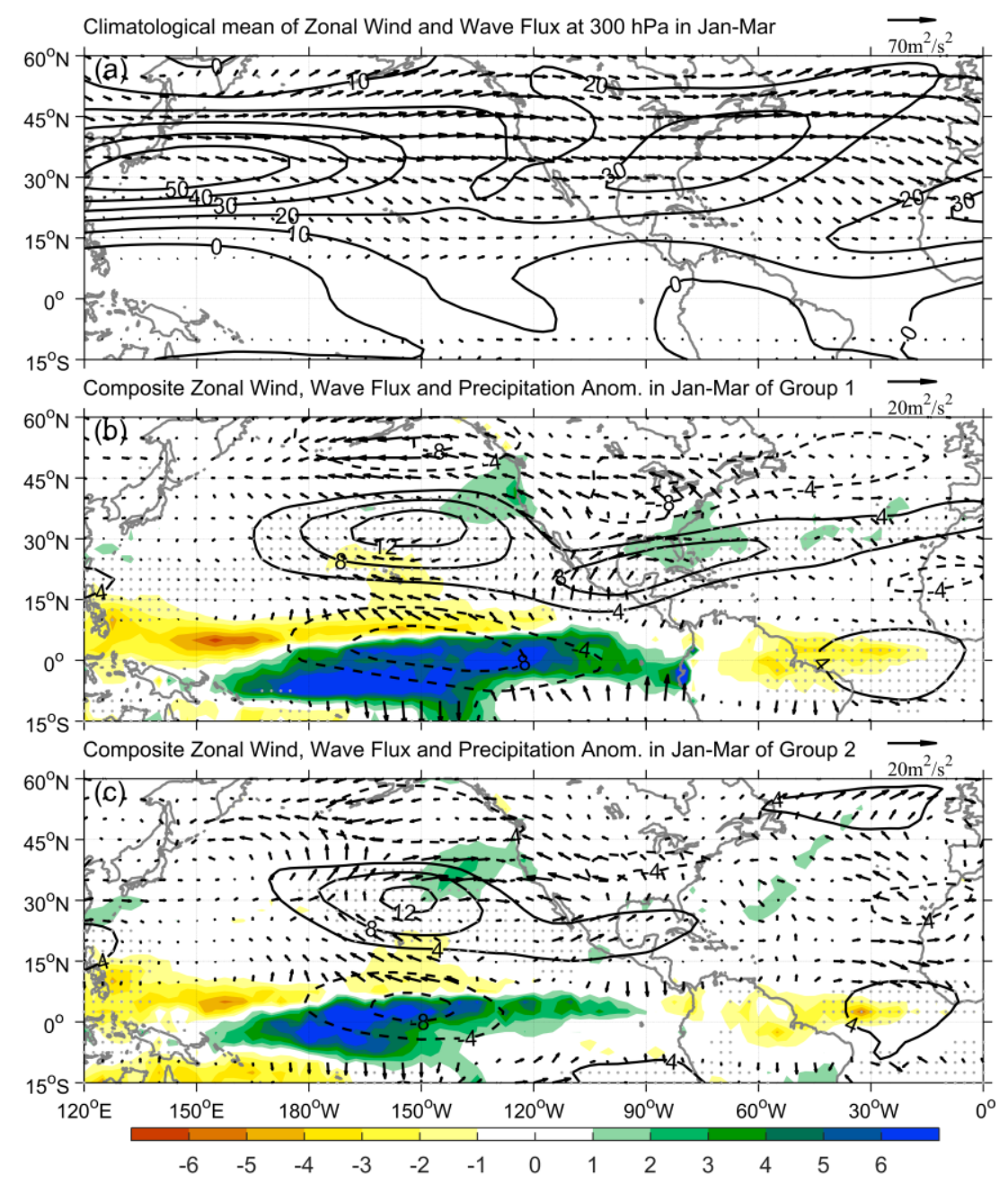

Figure 5.(a) Climatological Jan-Mar mean wave activity flux (vector) and zonal wind (contour, units: $m \cdot s^{-1}$ ) at $300 \mathrm{hPa}$. (b) Anomalous fields of zonal wind (contour, the solid is for positive anomaly and the dashed is for negative one, the interval is $4 \mathrm{~m}$. $s^{-1}$ ) and wave activity flux (vector) at $300 \mathrm{hPa}$, and of precipitation (shading, unit: $\mathrm{mm}$ day-1) for Jan-Mar of the composite El Niño event in Group 1. (c) The same as in Panel b but for Group 2. The stippling indicates the significance of anomalous westerlies exceeding $95 \%$ confidence level in (b, c) 

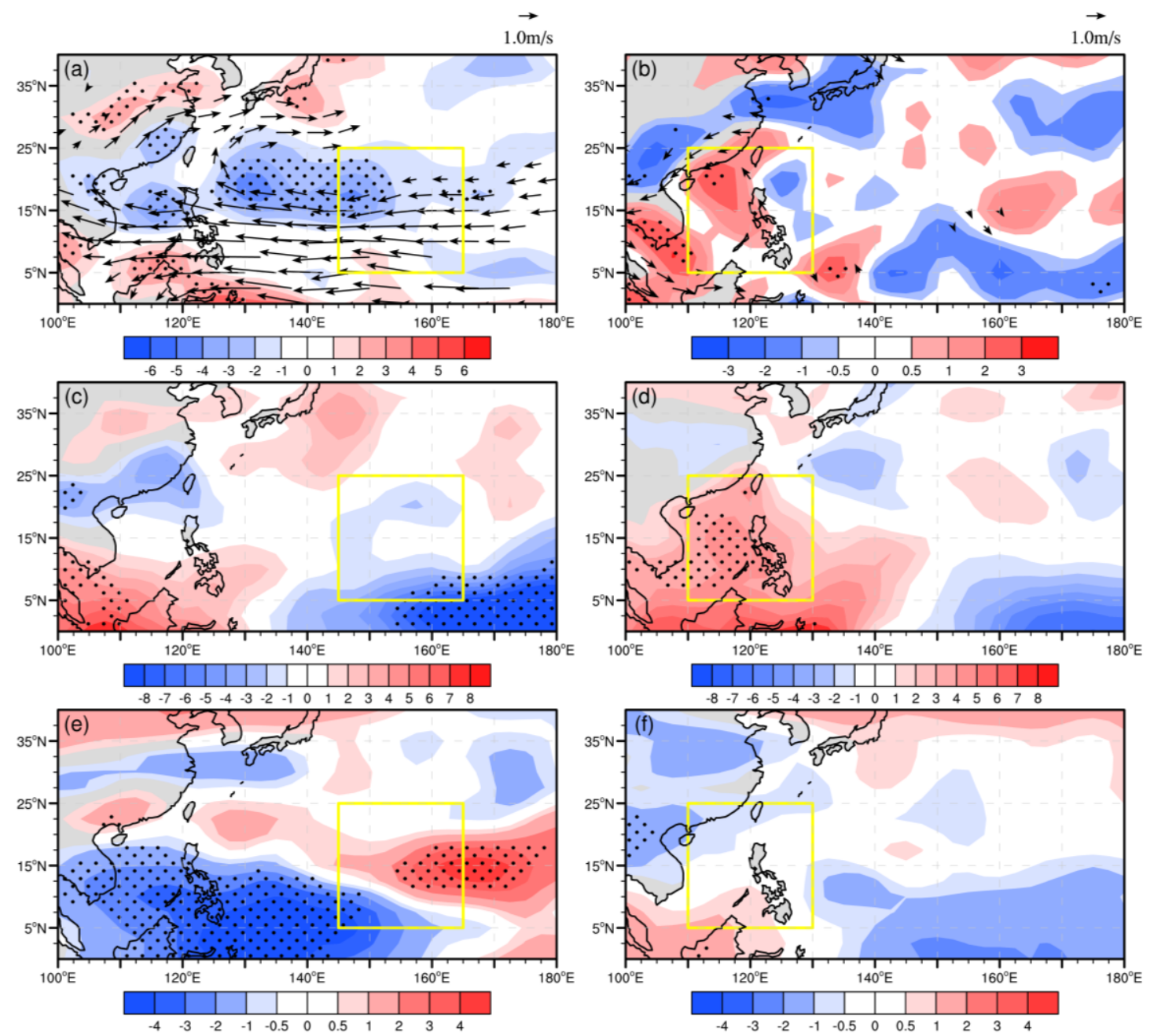

Figure 6. Anomalous fields of relative vorticity (contour, unit: $10^{-5} \mathrm{~s}^{-1}$ ) and wind vector (unit: $\mathrm{m} \mathrm{s}^{-1}$ ) at 850-hPa (a, b, upper panels), relative humidity at $600 \mathrm{hPa}(\mathrm{c}, \mathrm{d}$, middle panels, unit: \%) and zonal wind vertical shear between 200-hPa and 850-hPa (e, f, lower panels, unit: $\mathrm{m} \mathrm{s}^{-1}$ ) over the western North Pacific in the post-El Niño period from July to October for the composite events in Group 1 (left panels) and Group2 (right panels). The stippling indicates the significance of shading exceeding $95 \%$ confidence level and only the wind vector anomaly above the $95 \%$ confidence level is shown. Yellow squares represent areas where significant anomalous TC genesis from July to October is located. 

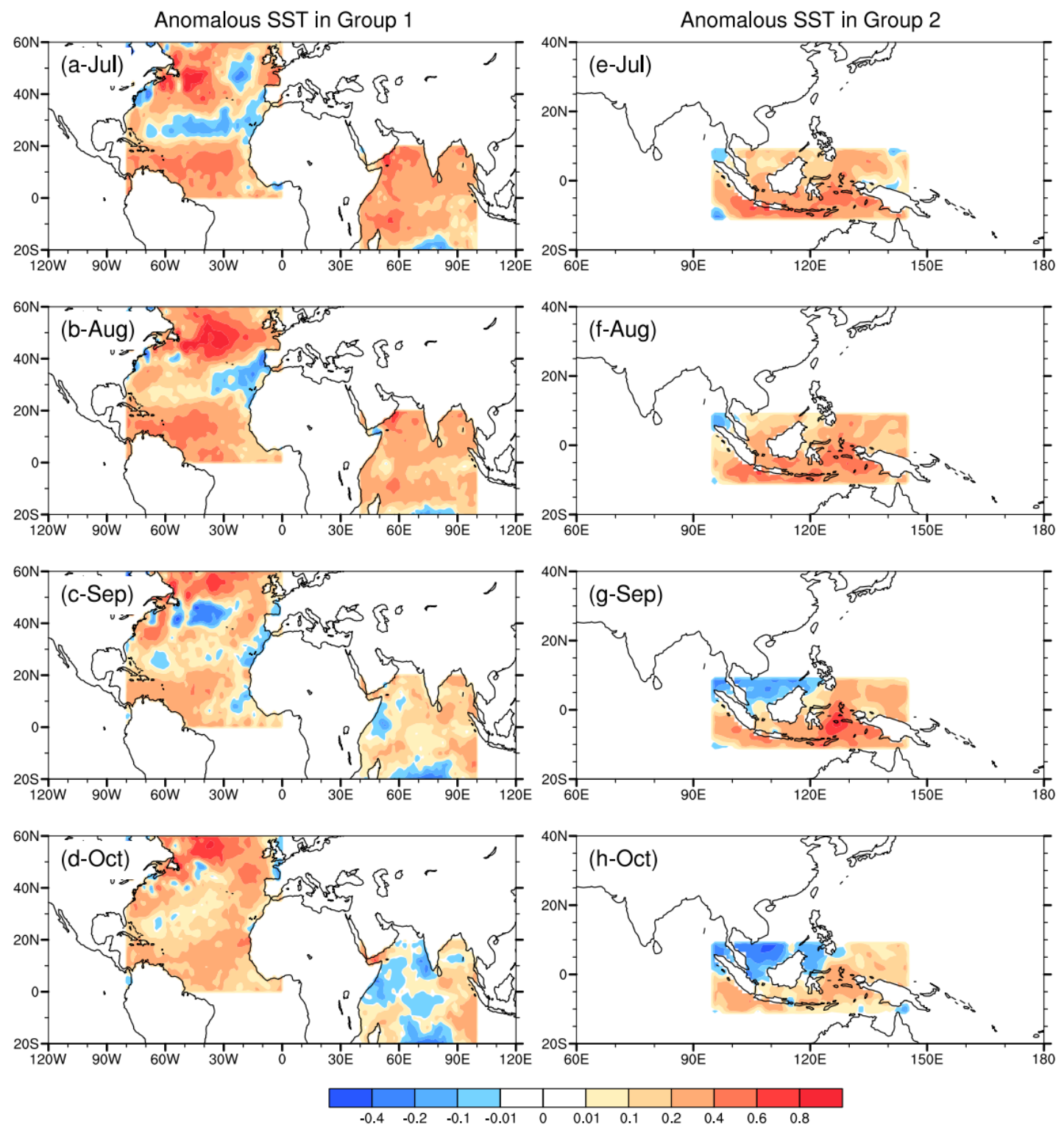

Figure 7 Anomalous SST implemented in numerical sensitivity experiments, corresponding to the post-El Niño phase (July to October after El Niño peaks in preceding December) of the composite El Niño in Group 1 and Group 2, respectively. El Niño in Group 1 (left) shows anomalies in the North Atlantic $\left(0^{\circ}-60^{\circ} \mathrm{N}, 80^{\circ} \mathrm{W}-0^{\circ}\right)$ and Indian Ocean $\left(20^{\circ} \mathrm{S}-20^{\circ} \mathrm{N}, 40^{\circ}-100^{\circ} \mathrm{E}\right)$, while El Niño in Group 2 (right) shows anomalies around the Maritime Continent $\left(11^{\circ} \mathrm{S}-9^{\circ} \mathrm{N}, 95^{\circ}-145^{\circ} \mathrm{E}\right)$. 

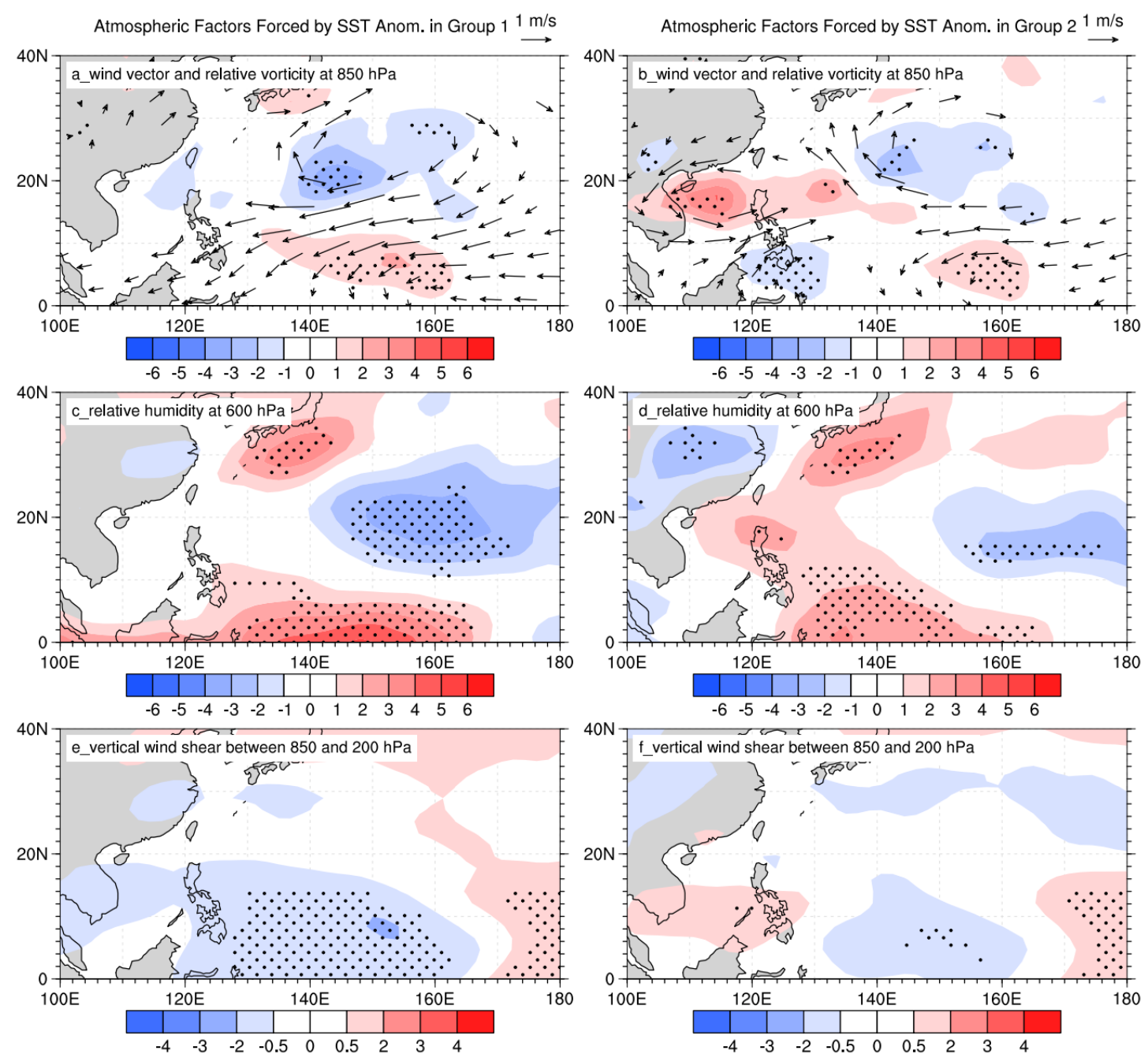

Figure 8. Response anomalies of relative vorticity (shading, unit: $10^{-6} \mathrm{~s}^{-1}$ ) and wind vector ( unit: $\mathrm{m} \mathrm{s}^{-1}$ ) at $850-\mathrm{hPa}(\mathrm{a}, \mathrm{b})$, relative humidity at $600 \mathrm{hPa}(\mathrm{c}, \mathrm{d}$ unit: \%) and vertical wind shear $\left(e, f\right.$, unit: $\left.\mathrm{m} \mathrm{s}^{-1}\right)$ in July-October over the western North Pacific to the composite SST anomalies over the North Atlantic $\left(0^{\circ}-60^{\circ} \mathrm{N}, 80^{\circ} \mathrm{W}-0^{\circ}\right)$ and Indian Ocean $\left(20^{\circ} \mathrm{S}-20^{\circ} \mathrm{N}, 40^{\circ}-100^{\circ} \mathrm{E}\right.$ ) ( a, c, e) for Group 1 and over the Maritime Content $\left(11^{\circ} \mathrm{S}-9^{\circ} \mathrm{N}, 95^{\circ}-145^{\circ} \mathrm{E} ; \mathrm{b}, \mathrm{d}, \mathrm{f}\right.$,) for Group 2 during El Niño decaying phase from ECHAM6.3 sensitivity simulations. Stippling means significance of shading exceeding 95\% confidence level and only the wind vector anomaly above the $95 \%$ confidence level is shown. 

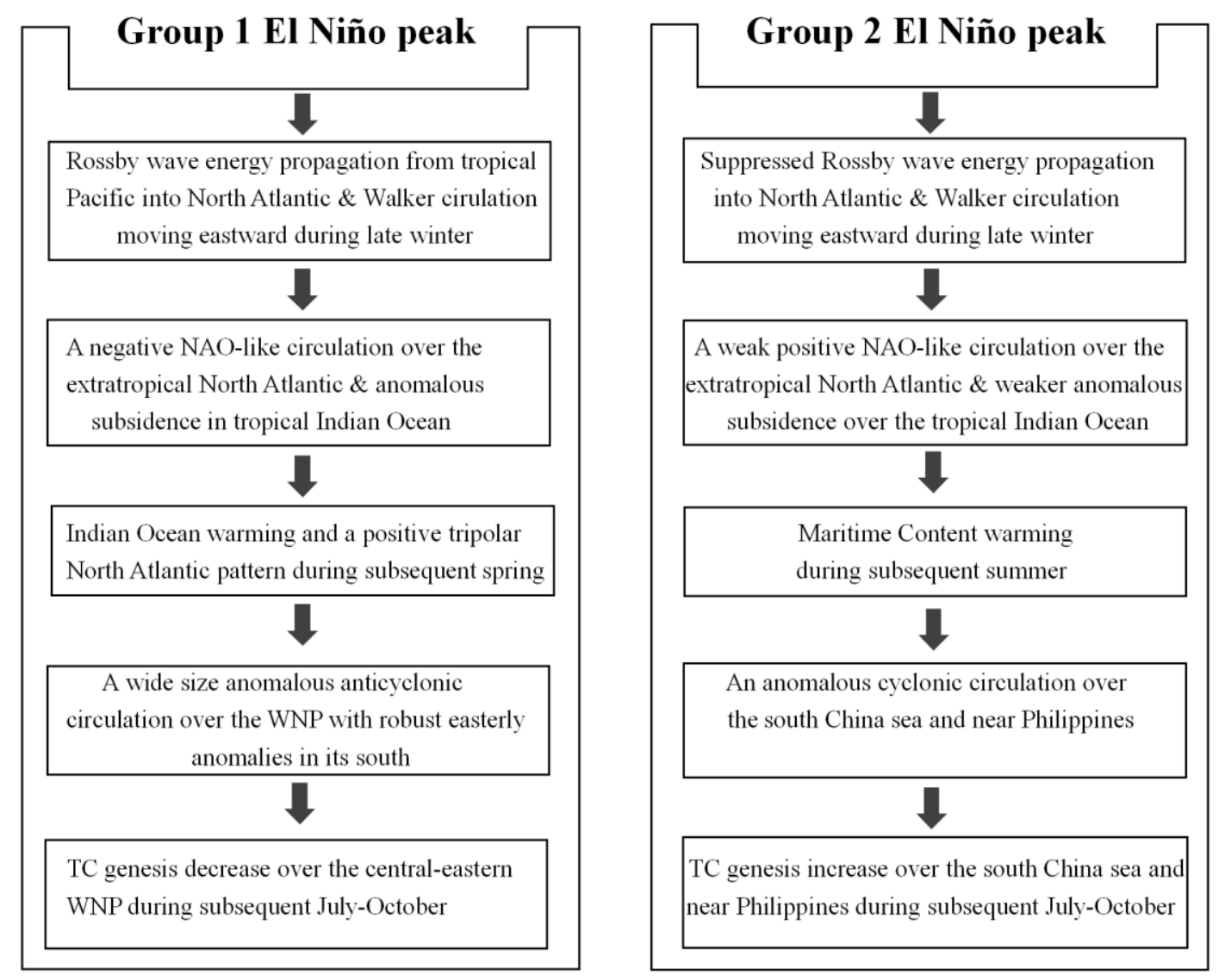

Figure 9 Schematic diagram of possible linkages between TC genesis decrease or increase in the WNP during July-October of El Niño decaying phase and EI Niño in its peak phase 